\title{
Analisis Ketercapaian Indikator pada Standar Pendidik dan Tenaga Kependidikan di SMP Muhammadiyah Cipanas
}

\author{
Iwan Setiawan, Chaerul Rochman, dan Bambang Syamsul Arifin \\ UIN Sunan Gunung Djati Bandung, Indonesia \\ email:acewicm87@gmail.com,chaerulrochman99@uinsgd.ac.id, \\ bambangsamsularifin@uinsgd.ac.id
}

\begin{abstract}
The study was conducted to analyze the achievement of standards of educators and education personnel. This is important to discuss to ensure the achievement of an institution in eight national education standards. This research method uses descriptive method. The participation of this research was 25 educators and education staff in SMP Muhammadiyah Cipanas Middle School, Cianjur Regency. The instrument used refers to nineteen standard indicators of educators and education personnel in the form of interview guidelines. The conclusions of this study are (1) the achievement profile of the standard indicators of educators and education personnel, showing varied results with an average achievement of $83 \%$; (2) indicators that have not reached the maximum score are certification teachers, BK teacher professionalism, BK Teacher Ratio, and Library Staff. Recommendations on the results of this study need an in-depth study of certification teachers and the ratio of $B K$ teachers in schools.
\end{abstract}

Keywords: Standard Of Teacher And Education Personnel, Indicator Achievement Of Teacher Sertivication, Teacher Counseling Ratio. 


\section{Pendahuluan}

Keberhasilan sebuah lembaga pendidikan sangat tergantung pada tenaga pendidik dan kepenedidikan atau utamanya pada kualitas guru, Berbagai masalah yang berkaitan dengan kondisi guru;(1) adanya keberagaman kemampuan guru dalam proses pembelajaran dan penguasaan pengetahuan, (2) belum adanya alat ukur yang akurat untuk mengetahui kemampuan guru, (3) pembinaan yang dilakukan belum mencerminkan kebutuhan guru dan (4) Kesejahteraan guru yang belum memadai. Jika hal tersebut tidak segera diatasi, maka akan berdampak pada rendahnya kualitas pendidikan.

Secara perlahan pemerintah mulai menunjukan perbaikan, hal ini ditunjukan dengan menetapkan standar pendidikan di indonesia. Hal ini berdasarkan PP No. 32 tahun 2013 tentang perubahan atas peraturan pemerintah no 19 tahun 2005 pasal 1 ayat 1 dan pasal 2 ayat 1 tentang standar nasional ada delapan standar nasional pendidikan yang dijadikan acuan pengembangan kurikulum untuk mewujudkan tujuan pendidikan nasional.

Standar nasional pendidikan, yaitu kriteria minimal tentang sistem pendidikan di seluruh wilayah hukum negara kesatuan republik indonesia, yaitu : 1) standar isi; 2) standar proses; 3) standar kompetensi lulusan; 4) standar kompetensi pendidik dan tenaga kependidikan; 5) standar sarana dan prasarana; 6) standar pengelolaan; 7) standar pembiayaan; 8) standar penilaian. Delapan standar di atas memiliki keterkaitan satu sama lain dan sebagian standar menjadi prasyarat bagi pemenuhan standar yang lainnya (Karenina, 2015 : 676-684).

Dari 8 (delapan) standar pendidikan tersebut berimplikasi pada upaya sekolah/ madrasah untuk menjadikan kualitas pendidikan yang dikelolanya menjadi lebih baik. Dari hasil survey yang dilakukan peneliti di SMP Muhammadiyah hasil akreditasi terbaru pada bulan Agustus 2017 menunjukan hasil memuaskan A dengan nilai rata-rata 92. Setelah mengobservasi lebih dalam khususnya pada standar pendidik dan tenaga kependidikan ada beberapa indikator yang belum mendapatkan nilai sempurna. Diantara indikator yang belum mendapatkan nilai sempurna adalah indikator nomor 39, 40, 45, 46, 49, 51, 54 dan 55.

Berdasarkan hasil survey tersebut peneliti tertarik untuk meneliti standar pendidik dan tenaga kependidikan di SMP Muhammadiyah Cipanas Kabupaten Cianjur dan mencari alternatif pemecahan masalah agar standar tersebut dapat mendapatkan nilai maksimal. 


\section{Metode Penelitian}

Metode penelitian ini menggunakan penelitian deskriptif partisipatoris. Partisipan dari penelitian ini adalah dua puluh lima pendidik dan tenaga kependidikan dari berbagai bidang studi dan keahlian yang ada di sekolah. Lokasi penelitian dilakukan di Muhammadiyah Cipanas Kabupaten Cianjur. Instrumen yang digunakan adalah pedoman wawancara yang bertujuan untuk mendapatkan informasi capaian dari standar pendidik dan tenaga kependidikan, dokumentasi untuk membandingkan hasil analisis wawancara dengan dokumen yang ada.

\section{Hasil Penelitian dan Pembahasan}

\section{Hasil Penelitian}

Ruang lingkup standar pendidik dan tenaga kependidikan berjumlah sembilan belas indikator terdiri dari:

1. Guru memiliki kualifikasi akademik minimum sarjana (S1) atau diploma empat (D4) dari program studi terakreditasi;

2. Guru memiliki sertifikat pendidik;

3. Guru mengampu mata pelajaran sesuai dengan latar belakang pendidikan dan/atau uji kelayakan dan kesetaraan;

4. Guru mata pelajaran memiliki kompetensi pedagogik, meliputi: (a) mengintegrasikan karakteristik siswa, (b) pembelajaran yang sesuai dengan karakteristik siswa, (c) merancang kegiatan pembelajaran siswa berdasarkan kurikulum, (d) menyelenggarakan pembelajaran yang mendidik, (e) menggunakan teknologi informasi dan komunikasi, (f) mengembangkan potensi siswa, (g) berkomunikasi secara efektif, empati, dan santun, (h) melaksanakan penilaian proses dan hasil belajar, (i) menggunakan hasil penilaian proses dan hasil belajar, (j) melakukan tindakan reflektif;

5. Guru memiliki kompetensi profesional, meliputi: (a) menguasai materi, struktur, konsep, dan pola pikir keilmuan yang mendukung mata pelajaran yang diampu, (b) menguasai kompetensi inti dan kompetensi dasar mata pelajaran yang diampu, (c) mengembangkan materi pembelajaran yang diampu secara kreatif, (d) mengembangkan keprofesian secara berkelanjutan dengan melakukan tindakan reflektif, (f) memanfaatkan teknologi informasi dan komunikasi;

6. Guru memiliki kompetensi kepribadian, meliputi: (a) bertindak sesuai dengan norma agama, hukum, sosial, dan kebudayaan, (b) menampilkan diri sebagai pribadi 
yang jujur, berakhlak mulia, dan teladan, (c) menampilkan diri sebagai pribadi yang mantap, stabil, dewasa, arif, dan berwibawa, (d) menunjukkan etos kerja, tanggung jawab, rasa bangga menjadi guru, dan rasa percaya diri, (e) menjunjung tinggi kode etik profesi;

7. Guru memiliki kompetensi sosial yang ditunjukkan melalui komunikasi yang efektif dan santun dengan: (a) sesama guru, (b) tenaga kependidikan, (c) siswa, (d) orangtua siswa, (e) masyarakat;

8. Guru Bimbingan Konseling (BK) memiliki kompetensi profesional yang meliputi: (a) penguasaan konsep dan praksis asesmen,(b) penguasaan kerangka teoretis dan praksis, (c) perencanaan program, (d) pelaksanaan program, (e) penilaian proses dan hasil kegiatan, (f) komitmen terhadap etika profesional, (g) penguaaan konsep dan praksis penelitian ;

9. Rasio antara Guru BK dengan jumlah siswa sesuai ketentuan, 1 (satu) Guru BK melayani maksimal 150 siswa;

10. Kepala sekolah/madrasah memenuhi persyaratan, meliputi: (a) memiliki kualifikasi akademik paling rendah sarjana S1 atau D4, (b) berusia maksimal 56 tahun, (c) sehat jasmani dan rohani, (d) tidak pernah dikenakan hukuman disiplin, (e) memiliki sertifikat pendidik, (f) memiliki sertifikat kepala sekolah/madrasah, (g) berpengalaman mengajar minimal 5 tahun, (h) golongan minimal III/c bagi PNS dan bagi non-PNS disetarakan, (i) nilai baik untuk penilaian kinerja dalam 2 tahun terakhir;

11. Kepala sekolah/madrasah memiliki kompetensi manajerial yang meliputi: (a) menyusun perencanaan, (b) mengembangkan organisasi, (c) memimpin penyelenggaraan sekolah/madrasah, (d) mengelola perubahan dan pengembangan, (e) menciptakan budaya kondusif dan inovatif, (f) mengelola guru dan tenaga administrasi, (g) mengelola sarana dan prasarana, (h) mengelola hubungan dengan masyarakat, (i) mengelola seleksi siswa, (j) mengelola pengembangan kurikulum dan kegiatan pembelajaran, (k) mengelola keuangan, (l) mengelola ketatausahaan, (m) mengelola unit layanan khusus, (n) mengelola sistem informasi, (o) memanfaatkan TIK, (v) melakukan monitoring, evaluasi, dan pelaporan;

12. Kepala sekolah/madrasah memiliki kemampuan kewirausahaan yang meliputi: (a) melakukan inovasi, (b) bekerja keras, (c) memiliki motivasi, (d) pantang menyerah dan selalu mencari solusi terbaik, (e) memiliki naluri kewirausahaan; 
13. Kepala sekolah/madrasah memiliki kemampuan supervisi akademik yang meliputi: (a) merencanakan program supervisi, (b) melaksanakan supervisi terhadap guru, (c) mengevaluasi hasil supervisi, (d) menindaklanjuti hasil supervisi;

14. Sekolah/madrasah memiliki Kepala Tenaga Administrasi dengan ketentuan: (a) kualifikasi minimal berpendidikan S1 dengan pengalaman kerja minimal 4 tahun, atau D3 dengan pengalaman kerja minimal 8 tahun, (b) memiliki sertifikat kepala tenaga administrasi sekolah/madrasah dari lembaga yang ditetapkan oleh pemerintah;

15. Sekolah/madrasah memiliki tenaga administrasi yang berkualifikasi akademik minimal SMA atau yang sederajat sesuai dengan bidang tugasnya;

16. Kepala perpustakaan memenuhi syarat sebagai berikut: (a) bagi jalur pendidik minimal S1/D4, memiliki sertifikat kompetensi, dan masa kerja 3 tahun, (b) bagi jalur tenaga kependidikan minimal D2, memiliki sertifikat kompetensi pengelolaan perpustakaan serta berpengalaman 4 tahun;

17. Tenaga Perpustakaan memiliki kualifikasi minimal SMA atau yang sederajat dan memiliki sertifikat kompetensi pengelolaan perpustakaan sekolah/madrasah;

18. Sekolah/madrasah memiliki laboran dengan kualifikasi akademik sesuai ketentuan standar tenaga laboratorium;

19. Sekolah/madrasah memiliki petugas yang melaksanakan layanan khusus, meliputi tugas: (a) penjaga keamanan, (b) tukang kebun, (c) tenaga kebersihan, (d) pesuruh, (e) pengemudi.

Data yang diperoleh berupa skor ketercapaian tiap indikator dengan ketentuan tiap indikator sebagai berikut :

\begin{tabular}{|l|l|l|}
\hline NO. & Ketercapaian indicator & Skor \\
\hline 1 & A $=$ Unggul & 4 \\
\hline 2 & B $=$ baik & 3 \\
\hline 3 & C $=$ cukup & 2 \\
\hline 4 & D $=$ Kurang & 1 \\
\hline 5 & E $=$ Sangat Kurang & 0 \\
\hline
\end{tabular}

Diadaptasi dari Evadir Akreditasi Tahun 2017

Dengan demikian, maka diperoleh jumlah skor maksimal adalah tujuh puluh enam (76). Rumus penghitunagn persentase setiap nilai adalah prosentasi ketercapaian $=\frac{\text { perolehan skor }}{\text { skor maksimum }} \times 100$ 
prosentasi ketercapaian $=\frac{\text { perolehan skor }}{\text { skor maksimum }} \times 100 \%$. adapun untuk menentukan kualifikasi prosentase ketercapaian digunakan tabel berikut :

\begin{tabular}{|l|l|l|}
\hline No. & Prosentase Ketercapaian & Kualifikasi \\
\hline 1 & $91 \%-100 \%$ & Unggul \\
\hline 2 & $81 \%-90 \%$ & Baik \\
\hline 3 & $71 \%-80 \%$ & Cukup \\
\hline 4 & $61 \%-70 \%$ & Kurang \\
\hline 5 & Kurang dari $61 \%$ & Sangat kurang \\
\hline
\end{tabular}

Diadaptasi dari Evadir Akreditasi Tahun 2017

Setelah diperoleh hasil analisis data. Maka dilanjutkan dengan triangulasi terhadap indikator-indikator yang belum maksimal dengan cara menanyakan masalah-masalah yang dihadapi dan langkah-langkah untuk solusinya.

\section{Pembahasan}

Berdasarkan hasil pengambilan dan analisis data tentang pencapaian Indikator pada standar pendidik dan tenaga kependidikan di SMP Muhammadiyah Cipanas Kabupaten Cianjur, maka dapat dijelaskan terkait dengan profil ketercapaian dan alternative pemecahan masalah sebagai berikut:

1. Profil Ketercapaian Indikator Standar Pendidik dan Tenaga Kependidikan

\section{Profil Pencapaian Indikator Standar PTK}

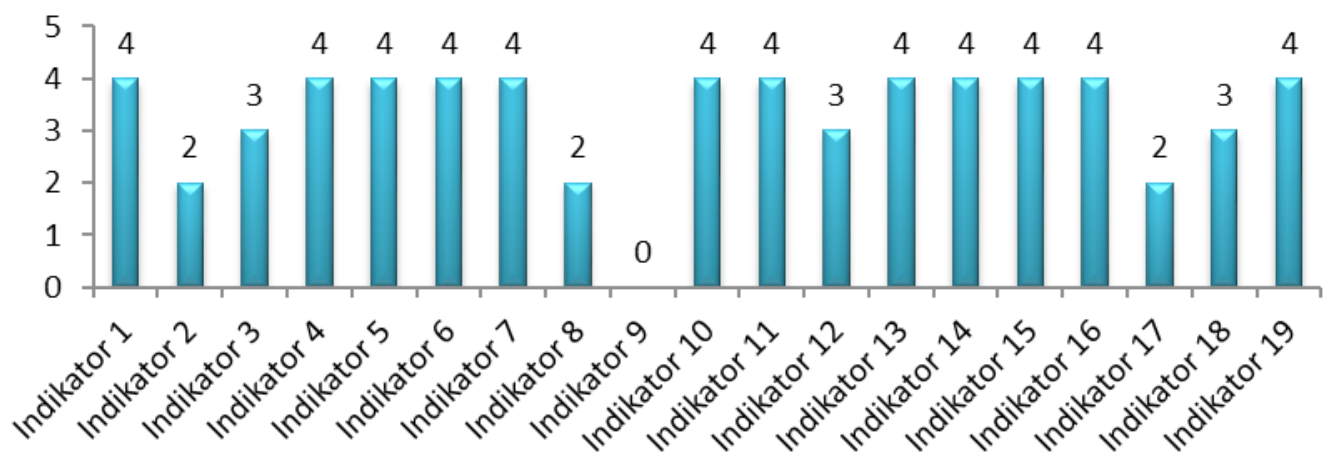

Grafik 1 Profil Ketercapaian Indikator Standar Pendidikdan Tenaga Kependidikan

Grafik 1 menunjukan prosil ketercapaian indikator standar pendidik dan tenaga kependidikan di SMP Muhammadiyah Cipanas Kabupaten Cianjur dari 19 indikator ada 12 indikator yang memperoleh nilai A, 3 indikator memperoleh nilai B, 3 indikator yang 
mendapatkan nilai $\mathrm{C}$, dan 1 indikator yang mendapatkan nilai $\mathrm{E}$. Dalam grafik digambarkan perolehan nilai A sama dengan 4, B sama dengan 3, C sama dengan 2, D sama dengan 1 dan E sama dengan 0. Indikator yang kurang dari 3 adalah indikator nomor 2 tentang guru yang telah tersertifikasi, indikator nomor 8 tentang Guru BK yang memiliki Kompetensi Profesional, Indikator nomor 9 tentang rasio guru BK, Indikator nomor 14 tentang kepala tenaga administrasi berkualifikasi S1 dan bersertifikat, dan indikator nomor 17 tentang tenaga perpustakaan yang belum memiliki sertifikat pengelolaan perpustakaan. Indikator nomor 2 menunjukan persentase $63 \%$, indikator nomor 8 menunjukan persentase 71 $\%$, indikator nomor 9 menunjukan persentase $33 \%$, indikator nomor 17 menunjukan persentase $50 \%$. Jumlah skor total yang dicapai pada standar pendidik dan tenaga kependidikan adalah 82 dari 95. Sehingga secara keseluruhan capaian standar pendidik dan tenaga kependidikan pada SMP Muhammadiyah Cipanas adalah 83 \%.

Berdasarkan analisis data di atas diketahui bahwa indikator yang belum mencapai skor optimal adalah; Pertama, mengenai guru yang telah tersertifikasi. Berdasarkan penelitian yang dilakukan Humphrey et.al. (2008: 1-63) berkata bahwa dengan berjalannya program sertivikasi evektif dalam penguatan kepemimpinan, memperkuat dasar pengetahuan, dan sebagai pengalaman tambahan bagi guru sesuai dengan latar belakang sekolah. Senada dengan itu Darling-Hammond et. Al. (2005: 42) Berkata Bahwa guru yang telah disertifikasi dengan guru yang belum disertfikasi tetapi menerima pelatihan keguruan sama efektifnya dengan guru bersertifikasi yang memiliki pengalaman yang sama. Dalam serangkaian analisis pretasi siswa kelas 4 dan 5 ditemukan bahwa guru yang bersertifikasi secara konsisten menghasilkan perolehan pretasi siswa yang lebih kuat dari pada guru yang tidak tersertivikasi. Sama halnya Boyd et. al. (2007: 45-68) Menyatakan bahwa guru yang mendapatkan nilai ujian sertifikasi dapat meningkatkan hasil belajar siswa, serta dengan adanya sertifikasi dapat mengurangi pelamar yang tidak memenuhi syarat menjadi guru tersertifikasi.

Kedua, tentang kompetensi profesional pada guru BK. Bemak et al. (2008:372-381) menyatakan Bahwa konseling berperan dalam mengurangi kesenjangan prestasi akademik siswa. Komepetensi yang dibutuhkan guru konseling adalah kompeten dalam budaya, pembela keadilan sosial, dan sebagai agen perubahan sosial. Senada dengan itu Ratts et al. (2007:2) menyatakan bahwa tenaga konseling memiliki peran sebagai agen perubahan sosial, dengan kompetensi yang dimilikinya ia berusaha untuk menyebarkan pesan bahwa semua siswa sama dan memiliki hak yang sama dalam mendapatkan pendidikan. 
Ketiga, tentang rasio perbandingan guru BK dengan siswa bahwa Zamroni et al (Zamroni: 2015) menyatakan bahwa rasio peraturan guru konseling di setiap sekolah adalah 150:1 dengan beban kerja 24 jam perminggu, berdasarkan anaklisisnya bahwa hal tersebut tidaklah cukup memenuhi kebutuhan layanan konseling kepada siswa secara individu dan menyeluruh pemberian jam layanan ke setiap kelas tidak dapat menjamin kebutuhan-kebutuhah layanan konseling dapat terpenuhi.

Keempat, mengenai tenaga perpustakaan yang bersertifikasi. Berdasarkan penelitian dengan membagikan 3000 kuesioner yang dilakukan Onal (Önal : 2005) menyatakan pustakawan sekolah berperan dalam menyediakan sumber daya informasi untuk membentu siswa di turki. agar pelayanan menjadi optimal maka diperlukan bimbingan penggunan agar pembimbingan menjadi lebih sempurna. Diperkuat lagi oleh Laksmi Dewi dan Asep Dudi Suhardini (Dewi: 2014) menyatakan bahwa bahwa dengan diadakannya pelatihan tentang kepeustakawanan dapat meningkatkan pengetahuan yang dimiliki staff perpustakaan, dilihat dari pre test dan post test terdapat perbedaan hasil ujian. Pelatihan perpustakaan terbukti efektif memberikan pengetahuan, sikap, dan aketerampilan dalam melaksanakan tugas mengelola perpustakaan

Berdasarkan hasil analisis data dan beberapa penelitian tentang program sertivikasi, profesinalisme Guru Bk, Rasio Perbandingan siswa dengan guru BK, dan Tenaga perpustakaan yang tersertifikasi, maka dapat dilakukan upaya-upaya yang berkaitan dengan program sertifikasi yaitu sekolah lebih tanggap dalam mengajukan guru-guru yang akan di sertifikasi karena program sertifikasi dapat menambah keilmuan guru dan selain itu secar atidak langsung guru yang tersertifikasi dapat meningkatkan prestasi anak di sekolah.

Berkaitan dengan profesionalisme guru BK, dibandingkan dengan hasil penelitian yang dilakukan oleh para peneliti banwa guru BK yang memiliki kemampuan profesional dapat menumbuhkan sikap keadilan kepada siswa melalui pelayanan-pelayanan yang dilakukan oleh guru-guru BK. Berkaitan dengan rasio perbandingan guru BK diharapkan sekolah bisa menambah guru BK sesuai dengan latar belakang pendidikan yang menjalur agar pelayanan terhadap siswa dapat lebih optimal, jika dibandingkan jumlah yang sesuai dengan undang-undang yang berlaku hal itu masih sangat kurang dalam memberikan pelayanan kepada siswa.

Terakhir berkaitan dengan pustakawan yang profesional, bahwa di negara-negara pustakawan sangatlah berperan dalam pengembangan pengetahuan pada anak berbeda 
dengan yang ada di SMP Muhammadiyah perpustakaan cenderung tertinggal dan kurang terawat. Berdasarkan hasil wawancara dengan petugas perpustakaan bahwa perpustakaan diharapkan bisa lebih terintegrasi dan lebih membantu anak dalam mengembangkan pengetahuan pada diri anak.

2. Analisi Kesulitan Ketercapaian Standar Pendidik dan Tenaga Kependidikan

Adapun kesulitan, analisi dan alternative pemecahan masalah ketercapaian indikator pada standara pendidik dan tenaga kependidikan dapat ditujukan dengan Gambar 1 berikut ini :

\section{Komposisi Indikator Standar PTK Berdasarkan Kualifikasi Pencapaian}

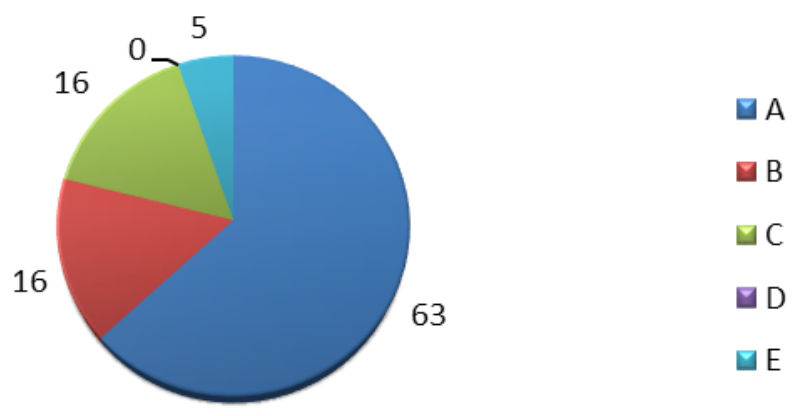

Gambar 1 Komposisi Indikator Standar PTK Berdasarkan Kualifikasi Pencapaian

Gambar 1 diatas menunjukan komposisi indikator berdasarkan kualifikasi capaian dari standar pendidik dan tenaga kependidikan. Berdasarkan hasil penghitungan setiap indikator didapatkan 12 indikator yang mendapatkan nilai A atau sebanyak 63\%, 3 indikator yang mendapatkan nilai $\mathrm{B}$ atau $16 \%, 3$ indikator yang mendapatkan nilai $\mathrm{C}$ atau $16 \%, 1$ indikator yang mendapatkan nilai $\mathrm{E}$ atau $5 \%$. Diantara indikator yang kurang dari 3 adalah indikator nomor 2 tentang guru sertifikasi, nomor 8 tentang profesionalisme guru BK, nomor 9 tentang Rasio Guru BK dengan Siswa dan nomor 17 tentang Tenaga perpustakaan.

Berdasarkan kesimpulan dari Abdirachman Purnomo (Purnomo:2016), kualifikasi tenaga pendidik di SMP N 4 prambanan sudah sesuai dengen permendiknas no, 16 tahun 2007. Untuk guru BK yang ada di SMP 4 prambanan memiliki kualifikasi sesuai dengan permendiknas no. 27 tahun 2008, sedangkan tenaga administrasi yang hanya lulusan 
SMA yang harus mendapatkan perbaikan. Sedangkan menurut Rahidi Amara (Asmara : 2015) meneliti tentang analisis implementasi standar nasional pendidikan pada SMP yang terakreditasi A di kabupaten seluma, menunjukan masih banyak kriteria yang belum terpenuhi dalam pengembangan kualitas sekolah diharapkan untuk memenuhinya yaitu sekolah menambah guru dan meningkatkan kemampuan guru dalam segala aspek.

Dengan demikian berbagai kesulitan yang dialami untuk mencapai indikator 2, 8, 9 dan 17 adalah sekolah diharapkan dapat menambah guru seperti guru BK dan meningkatkan kemampuan guru-guru seperti guru BK dan tenaga perpustakaan serta guru-guru yang belum mendapatkan sertifikasi. Guna mengembangkan kemampuan pendidik dan tenaga kependidikan yang masih kurang maka diharapkan sekolah dapat mengembangkan berbagai kemampuan guru melalui pelatihan-pelatihan berdasarkan kemampuan guru yang kemampuannya masih kurang.

\section{Analisis Kesulitan Ketercapaian Standar Pendidik dan Tenaga Kependidikan}

Adapun kesulitan, analisis dan alternative pemecahan masalah ketercapaian indikator pada standar pendidik dan tenaga kependidikan dapat ditunjukan dalam tabel berikut:

Indikator nomor 2

\begin{tabular}{|l|l|l|}
\hline \multicolumn{1}{|c|}{ Responden } & \multicolumn{1}{|c|}{ Masalah } & \multicolumn{1}{|c|}{ Solusi } \\
\hline Bapak Dede Suherlan & Tidak memiliki sertifikasi \\
pendidik & $\begin{array}{l}\text { Diharapkan tidak banyak } \\
\text { persyaratan untuk mengikuti } \\
\text { sertivikasi }\end{array}$ \\
\hline Ibu Fenty & Tidak memiliki sertivikat \\
& pendik & $\begin{array}{l}\text { Diharapkan sekolah } \\
\text { lebih memperhatikan dan } \\
\text { mengajukan guru-guru yang } \\
\text { belum memiliki sertivikat } \\
\text { pendidik untuk mengikuti } \\
\text { sertifikasi pendidik yang } \\
\text { diselenggarakan oleh } \\
\text { lembaga yang di tunjuk oleh } \\
\text { pemerintah. }\end{array}$ \\
\hline
\end{tabular}


Indikator nomor 8

\begin{tabular}{|c|l|l|}
\hline Responden & \multicolumn{1}{|c|}{ Masalah } & \multicolumn{1}{|c|}{ Solusi } \\
\hline Bapak Yana Suryana & Kompetensi profesional & $\begin{array}{l}\text { Diharapkan sekolah dapat } \\
\text { mengirimkan guru BK } \\
\text { tenaga konseling }\end{array}$ \\
& & $\begin{array}{l}\text { pada seminar-seminar atau } \\
\text { pelatihan tentang BK. }\end{array}$ \\
\hline
\end{tabular}

Indikator nomor 9

\begin{tabular}{|c|l|l|}
\hline \multicolumn{1}{|c|}{ Responden } & \multicolumn{1}{|c|}{ Masalah } & \multicolumn{1}{c|}{ Solusi } \\
\hline Bapak Yana Suryana & Rasio gur BK & $\begin{array}{l}\text { Diharapkan sekolah dapat } \\
\text { merekrut guru BK yang baru. } \\
\text { Agar proses konseling dapat } \\
\text { berjalan secara maksimal }\end{array}$ \\
\hline
\end{tabular}

Indikator nomor 17

\begin{tabular}{|l|l|l|}
\hline Responsen & \multicolumn{1}{|c|}{ Masalah } & \multicolumn{1}{|c|}{ Solusi } \\
\hline Bapak Riska & Tenaga perpustakaan & $\begin{array}{l}\text { Karena kurangnya tenaga } \\
\text { perpustakaan menjadikan } \\
\text { perpustakaan kurang terawat } \\
\text { diharapkandengan pemberian } \\
\text { waktu yang cukup untuk } \\
\text { berbenah perpustakaan maka } \\
\text { perpustakaan bisa menjadi } \\
\text { tempat yang lebih baik dan } \\
\text { bermanfaat bagi seluruh } \\
\text { siswa di sekolah. Mengenai } \\
\text { sertifikat diharapkan sekolah } \\
\text { dapat mengutus tenaga } \\
\text { perpustakaan ke pelatihan } \\
\text { pengelola perpustakaan di } \\
\text { lembaga yang pemerintah } \\
\text { tetapkan. }\end{array}$ \\
\hline
\end{tabular}

Tabel 1. Analisis Kesulitan guru serta alternatif pemecahan masalah

Tabel 1 menunjukan analisis kesulitan yang dialami oleh pendidik dan tenaga kependidikan di SMP Muhammadiyah. Dari 19 indikator ada 4 indikator yang yang perlu dibahas diantaranya : 


\section{a. Indikator 2}

Terdapat 8 orang guru yang belum tersertifikasi dianatarnya adalah Yana Suryana, Fenty Erdianti, Yanti Nurmayanti, Afrizal Kamil, Abdul Aziz, Trihandaya, Titi Sutiati, Nurani Puspita Sari, Alterhatif pemecahan masalahnya adalah diharapkan sekolah dapat mengajukan guru-guru untuk mengikuti pelatihan sertifikasi dan diharapkan pemerintah tidak membebani guru-guru yang akan melakukan sertifikasi dengan syarat yang banyak dan rumit.

b. Indikator 8

Dianatara kelemahan yang lain yaitu guru BK merupakan guru yang bukan dari lulusan konseling sehingga kegiatan konseling kurang berjalan dengan maksimal. Untuk alternatif pemecahan masalah berdasarkan wawancara yang dilakukan dengan guru BK di SMP Muhammadiyah Cipanas adalah diharapkan sekolah dapat mengirim guru BK pada seminar-seminar atau pelatihan tentang BK.

c. Indikator 9

Permasalah pada indikator ini adalah kurangnya guru BK di SMP Muhammadiyah Cipanas rasio minimum yang ditetapkan adalah 1 guru BK melayani 150 siswa. Sedangkan sekolah hanya memiliki 1 guru BK untuk siswa sekitar 500 orang. Alternatif pemecahan masalah dari permasalahan ini adalah diharapkan sekolah dapat merekrut guru BK yang baru.

\section{d. Indikator 17}

Tenaga perpustakaan yang masih kurang menjadi salah satu masalah yang ada di SMP Muhammadiyah. Tidak ada tenaga pustakawan, ada juga tenaga perpustakaan yang diangkat tapi tidak sesuai dengan jurusan perpustakaan, sehingga perpustakaan kurang terawat dan penataan buku tidak sesuai dengan katalog atau indeksnya. Alternatif pemecahan masalah adalah dengan merekrut petugas perpustakaan untuk membantu tenaga perpustakaan dalam merawat kebersihan dan kerapihan perpustakaan di SMP Muhammadiyah Cipanas Kabupaten Cianjur.

Berdasarkan hasil wawancara di atas bahwa indikator yang sangat mengalami kekurangan adalah indikator nomor 9 mengenai rasio perbandingan guru BK dengan peserta didik. Seperti halnya yang diungkapkan oleh Irawansa dkk (Irawansa:2016), dalam jurnalnya menyatakan bahwa perbandingan yang tidak sesuai antara guru BK dengan peserta didik dapat mengakibatkan pelayanan konseling yang kurang maksimal, 
dan dapat menambah angka pelanggaran di sekolah diakibatkan kurang maksimalnya pelayanan BK di sekolah. Berdasarkan hasil analisis hasil wawancara yang dilakukan tentang rasio guru BK maka dapat dilakukan upaya berupa penambahan guru BK di SMP Muhammadiyah agar pelaksanaan program konseling lebih maksimal dan penurunan jumlah pelanggaran di sekolah.

\section{Kesimpulan}

Berdasarkan analisis yang dilakukan di SMP Muhammadiyah Cipanas bahwa secara keseluruhan pada standar pendidik dan tenaga kependidikan mendapatkan persentase sebesar 86,3\%. Dengan rincian nilai A sebanyak 11 indikator atau 63,2 \%, nilai B sebanyak 3 indikator atau 15,8 \%, nilai $\mathrm{C}$ sebanyak 4 indikator atau 15,8 \%, nilai E sebanyak 1 indikator atau 5,3\%. Untuk memaksimalkan setiap indikator yang masih kurang dari B maka beberapa solusi yang diharapkan yaitu dengan lebih banyak mengirimkan guruguru kepelatihan sesuai bidang keahlian guru tersebut, dengan merekrut guru BK yang masih sangat kurang, dengan berkerjasama dengan murid-murid agar perpustakaan lebi terintegrasi.

\section{Daftar Pustaka}

Asmara, Rahidi. “Analisis Implementasi Delapan Standar Nasionalpendidikan Pada SMP Yang Terakreditasi A Di Kebupaten Seluma." Manajer Pendidikan 9, no. 2 (2015). Abdirachmat Purnomo. "Analisis Pemenuhan Standar Nasional Pendidikan (SNP) Di SMP N 4 Prambanan”. Jurnal Hanata Widya. (2016).

Darling-Hammond, Linda, Deborah J. Holtzman, Su Jin Gatlin, and Julian Vasquez Heilig. "Does teacher preparation matter? Evidence about teacher certification, Teach for America, and teacher effectiveness." education policy analysis archives 13 (2005).Ida Kiantamani Dewi Hermawan. "Evalusi Program SMP Standar Nasional Berdasarkan Standar Nasional Pendidikan" Jurnal Pendidikn dan Kebudayaan. Vol. 17 No. 6 (2011)

Dewi, Laksmi, and Asep Dudi Suhardini. "Peran perpustakaan dan tenaga perpustakaan sekolah/madrasah dalam meningkatkan mutu pendidikan di sekolah/madrasah." (2014)Indonesia, Republik. "Undang-undang Republik Indonesia nomor 20 tahun 2003 tentang sistem pendidikan nasional." Jakarta: Pemerintah Republik Indonesia (2003).

| Volume. 4, No. 1, Januari - Juni 2019 
Humphrey, Daniel C., Marjorie E. Wechsler, and Heather J. Hough. "Characteristics of effective alternative teacher certification programs." Teachers College Record 110, no. 1 (2008).

Irwansa, A., and MUH ARSYAD MAF'UL. "Analisis Pelaksanaan Tata Tertib Sekolah pada Siswa di SMK Negeri 1 Makassar.” Jurnal Tomalebbi 2, no. 1 (2016).

Karenina, Aziza, Dewi Anjani, Shinta Devi Amielia, and Sajidan Sajidan. "Profil Pemenuhan Standar Nasional Pendidikan, Ketuntasan Belajar Berbasis UN dan Proses Pembelajaran di Salah Satu Sekolah Menengah Pertama di Kab. Magetan.” In Prosiding SNPS (Seminar Nasional Pendidikan Sains), vol. 2, pp. 676-684. 2015.

Lubis, Asri. "Pelaksanaan Standar Nasional Dalam Dunia Pendidikan." - (2013).

Önal, H. İnci. "New developments on the Turkish school library scene." Journal of librarianship and Information Science 37, no. 3 (2005).

Purnomo, Abdi Rachmat. "Analisi Pemenuhan Standar Nasional Pendidikan (Snp) Di Smp N 4 Prambanan." Hanata Widya 5, no. 6 (2016).

Ratts, Manivong J., Lorraine DeKruyf, and Stuart F. Chen-Hayes. "The ACA advocacy competencies: A social justice advocacy framework for professional school counselors."ProfessionalSchoolCounseling11,no.2(2007):2156759X0701100203.

Zamroni, Edris, and Susilo Rahardjo. "Manajemen bimbingan dan konseling berbasis permendikbud nomor 111 tahun 2014.” Jurnal konseling gusjigang 1, no. 1 (2015). 